\title{
Formação inicial de professores no embalo das ações didáticas: possiblidades para a autonomia docente
}

\section{Training teachers in initial actions embalo of teaching: possibilities for} teaching autonomy

\author{
Marly Macêdo* \\ Pontifícia Universidade Católica do Paraná \\ Joana Paulin Romanowski** \\ Pontifícia Universidade Católica do Paraná \\ Pura Lúcia Oliver Martins*** \\ Pontifícia Universidade Católica do Paraná
}

Resumo Este artigo tem por objetivo analisar a Didática na formação inicial do professor no curso de Pedagogia em sua relação com a prática docente. Problematiza a Didática enquanto disciplina voltada à formação de professores articulada à prática docente. A metodologia é de abordagem qualitativa e a análise toma por base registros dos estudantes, coletados na autoavaliação da disciplina Didática do curso de Pedagogia de uma IES da cidade de Curitiba. Os aportes do estudos incluem Martins, Veiga, Romanowski, Santos e outros, que discutem a compreensão dessa disciplina e sua interlocução com a prática para a formação de professores. Os resultados mostram que a Didática possibilita aos estudantes a compreensão das situações de aprendizagens, tendo como ponto de partida a prática social problematizada a partir das vivências e experiências dos docentes e discentes da escola básica.

PalaVRAS-ChaVE: Didática; Formação de professores; Curso de Pedagogia.

Abstract This article aims to analyze Didactics in the initial formation of the teacher in the course of Pedagogy in its relations with the teaching practice. Problematizes Didactics as a discipline focused on teacher formation articulated to teaching practice. The methodology is a qualitative approach and the analysis is based on student narrative collected in the self-assessment of the Didactics course of the course of Pedagogy of an IES in the city of Curitiba. The contributions of the studies include Martins, Veiga, Romanowski and Santos, and others, who discuss the understanding of this discipline and its interlocution with the practice for the formation of teachers. The results show that Didactics enables students to understand learning situations based on the problematic social practice based on the experiences and experiences of the teachers and students of the basic school.

KEYWORDS: Didactics; Teacher formation; Course of Pedagogy. 


\section{Introdução}

A formação inicial do professor tem sido alvo de inúmeras discussões no contexto da educação brasileira mediadas por eventos educacionais, como congressos, seminários, simpósios, fóruns dentre outros que tratam dessa temática. Evidenciando uma preocupação dos estudiosos que defendem ser a formação de professores um dos indicadores na melhoria da qualidade na educação, quer seja em âmbito local, regional, nacional e internacional como indica Marcelo, (1999), Imbernóm (2010), Gatti, Barreto e André (2011), entre outros. O pressuposto é de que uma formação substantiva favorece uma atuação docente que proporciona um ensino e aprendizagem consistente na educação básica.

Além disso, os autores postulam que a formação deve contribuir para a profissionalização docente elevando o estatuto profissional pela atuação e valoração social da categoria, aos quais se agregam o reconhecimento da identidade docente não dissociada da pessoa e do professor. Com efeito, Nóvoa (2009, p. 205), ao discutir a profissão docente afirma que ela "não é natural, mas construída na definição pública de uma posição com forte sentido cultural, numa profissionalidade docente que não pode deixar de se construir no interior de uma pessoalidade do professor".

$\mathrm{Na}$ discussão dos conhecimentos constitutivos, inerentes aos professores, Shulman (1986) indica entre eles o conhecimento pedagógico, referentes a aula, que envolvem a matéria a ser ensinada, a matéria ensinada e a matéria aprendida (ROMANOWSKI, 2016). Nesse campo, os conhecimentos didáticos são basilares (VEIGA, 2012) ao se constituírem compósito ${ }^{1}$ teórico sobre o processo de ensino e aprendizagem, portanto conhecimentos estruturantes no campo da formação docente (ROLDÃO, 2007). Essa autora afirma que são conhecimentos definidores da profissão - nomeadamente a função docente e sua natureza - o desempenho docente, são componentes do conhecimento profissional necessário ao seu desempenho. Nesse sentido, a Didática é uma disciplina que compõe esse campo formativo. Assim os conhecimentos assumem a dimensão da relação teoria e prática entendendo a teoria como expressão da prática (MARTINS, 2012).

Nesse artigo, propomos analisar a Didática na formação inicial de professores, tomando como referência uma pesquisa realizada nessa disciplina com o objetivo de compreender quais as suas contribuições para a formação docente. Nesse sentido, propomos buscar respostas para os questionamentos que se seguem: Quais as contribuições da Didática para a formação do professor? Como os estudantes do curso de Pedagogia compreendem a importância da Didática para sua formação docente? Como organizar e acompanhar a disciplina Didática na ação docente, considerando os referenciais de formação que procuramos integrar ao contexto das licenciaturas, tais como o desenvolvimento da autonomia, da criatividade, da criticidade e da reflexão, advindas de uma postura de pesquisador diante da prática? Por fim, como despertar no licenciando a consciência da importância da docência para sua formação inicial e para a qualidade do desempenho do professor?

A pesquisa foi realizada em um curso de Pedagogia de uma IES da cidade de Curitiba, que oferta o curso desde longa data. No curso, a Didática está desdobrada em três semestres letivos: fundamentos de didática, didática na ação docente, didática 
na organização do trabalho pedagógico. O foco do estudo considera os resultados de uma autoavaliação feita com 31 estudantes da Licenciatura Pedagogia, no contexto da disciplina Didática na Ação Docente. A análise incidiu sobre as aprendizagens e reflexões sobre sua formação expressas pelos estudantes.

A abordagem da disciplina entende a articulação com a prática docente, assim o processo metodológico foi fundamentado na Sistematização Coletiva do Conhecimento, em que as ações são construídas de forma coletiva, materializado na intencionalidade da prática docente, em que professores e discentes, juntos, constroem formas de pensar, sentir e agir tomando como ponto de partida a prática docente e seus desafios. Nesse sentido, destacamos as proposições de Martins (2012, p. 94) que desenvolve os pressupostos da teoria como expressão da prática por meio dos seguintes passos:

a) caracterização e problematização da pratica social, comum a professores e alunos; b) explicação da prática, mediatizada por um referencial teórico; c) compreensão da prática, na totalidade; d) elaboração de propostas de intervenção na prática, tendo em vista a sua transformação. (grifos da autora).

A transformação se dá pela análise da prática balizada pela teoria da didática e da educação, favorecendo a compreensão da prática pelo docente. Ao compreender os determinantes dessa prática, o docente sistematiza seus saberes que se constituem novos pontos de partida para o enfrentamento de situações desta prática.

Assim, procuramos desdobrar nossa escrita a partir de agora em dois momentos. Inicialmente refletimos sobre a Formação de Professores, sempre situando a Didática no processo formativo, em sequência, trazemos os resultados da investigação sobre as contribuições da Didática, bem como sobre a metodologia utilizada na disciplina, numa perspectiva de análise compreensiva em que a descrição e interpretação a constituem (SANTOS, 2005).

\section{Didática na formação de professores}

Investigar a área da Formação de Professores é um desafio frente a sua amplitude e complexidade. O ser humano, como ser social que é, produz conhecimentos, tanto do senso comum quanto ligados as diversas áreas, tais como a filosófica, sociológica, psicológica, espiritual ou científica. Essa inquietação, por conhecer parte das necessidades individuais e coletivas, instiga-o na busca de uma formação mais sistemática, frente a sociedade do conhecimento orquestrada pelos avanços das novas tecnologias da comunicação e informação, portanto, cada vez mais, nos movemos na produção de conhecimentos que nos proporcionem conviver e interagir nesse devir. Segundo Marcelo (1999, p. 11) "todos exigimos e reconhecemos a necessidade de formação, sobretudo num mundo em que a informação nos chega cada vez com mais facilidade e, portanto, nos faz ver o quanto desconhecemos e deveríamos ou gostaríamos de saber".

Em se tratando da formação de professores, entendemos que se refere a uma linha de pesquisa e estudo que procura abarcar a complexidade existente no cam- 
po formativo do profissional da educação, envolta em múltiplas dimensões e que, de certo modo, termina por dificultar seu entendimento, ora identificando-a com a Prática profissional, ora endereçando-a aos processos de formação inicial, ao desenvolvimento profissional ou formação continuada. É preciso, portanto, entender a Formação de Professores considerando sua complexidade, sem entretanto deixar de perceber suas particularidades e a interdependência entre essas etapas.

Partindo desse pressuposto, podemos conceituar a área ou campo de estudo "Formação de Professores" a partir de seu objeto de pesquisa e suas singularidades como apresenta Marcelo (1999, p. 25): “[...] a formação de professores possui um objecto de estudo singular, que são, como já antes descrevemos, os processos de formação, preparação, profissionalização e socialização dos professores." (grifos do autor). As singularidades, expressas por Marcelo (Ibidem), dizem respeito aos elementos que caracterizam a área de investigação e que precisam ser reconhecidos pelos estudiosos. O autor aponta cinco elementos: (1) o reconhecimento do objeto de estudo e sua complexidade; (2) as diversas estratégias e metodologias consolidadas nessa área de estudo; (3) a apropriação de um código próprio da comunidade científica para essa área de estudo; (4) a incorporação ativa dos professores, protagonistas dessa área de interesse; por último, (5) a importância da formação de professores como elemento fundante da qualidade da prática docente reconhecida por políticos, administradores e pesquisadores, com maior interesse em intervir no campo macro.

Roldão (2007), ao organizar o Estado da Arte sobre pesquisas realizadas no campo da Formação de Professores em Portugal, no período de 1994 a 2003, apontou para uma dispersão nas temáticas e referenciais, o que demonstra os diálogos interdisciplinares que esse campo propicia, mas ao mesmo tempo impera certa dificuldade de definição do objeto de estudo, levando a autora a delimitar, para fins de análise, aquilo que diz respeito ao campo de estudo e aos elementos coadjuvantes que a ele se relacionam. A autora, reconhecendo a complexidade dessa área, a delimita e conceitua como:

[...] o próprio campo da formação de professores, ou seja, o 'como' do aprender e/ou desenvolver e melhorar o 'ser professor' e o 'saber ser professor', referenciando no âmbito desta denominação os processos de aprendizagem e desenvolvimento da construção do conhecimento e do desempenho profissional dos docentes. (Ibid., p.53, grifos da autora).

Ainda, tomando como referência os estudos de Roldão, que caracteriza os campos adjacentes, exteriores ao campo nuclear da área Formação de Professores, identificamos sua proximidade com outros campos do conhecimento, caracterizando suas interfaces. A autora aponta como campo nuclear ou núcleo central os "conceitos estruturantes", "Estudo dos processos de construção e desenvolvimento do conhecimento e do desempenho profissional docente" e, ainda, as "Dimensões de operacionalização da formação". Nos campos exteriores ou adjacentes identifica o "Currículo, Cultura Profissional, Concepções e percursos dos professores, as Didácticas e Culturas Organizacionais". Além dessas áreas também se encontra em sua pesquisa campos próximos, relacionados a "Formação em outros contextos". (Ibid., p.54). Dessa forma, a Didática é um dos elementos exteriores ao campo nuclear ou núcleo central da For- 
mação de Professores, mas está diretamente relacionada com a formação e, de algum, modo alimenta o seu saber e molda o seu desempenho (ROLDÃO, 2007).

Nessa perspectiva, a Didática é considerada uma das disciplinas teórico -prática comprometida com a formação do professor, de modo especial com a prática docente. Em conformidade com a legislação brasileira, a Resolução 02/2015 que define as Diretrizes Curriculares Nacionais para a formação inicial em nível superior e para a formação continuada, aponta a prática enquanto componente curricular e que deve permear todo o processo formativo. Essa Resolução prescreve (Art. 13, § $3^{\circ}$ ) que: "Deverá ser garantida, ao longo do processo, efetiva e concomitante relação entre teoria e prática, ambas fornecendo elementos básicos para o desenvolvimento dos conhecimentos e habilidades necessários à docência".

Diante do exposto levantamos os seguintes questionamentos: que contribuições a Didática, enquanto disciplina voltada para a prática docente, está trazendo para a formação inicial do licenciando do curso de Pedagogia? De que forma estão sendo organizadas e realizadas as atividades didático-pedagógicas nos cursos de formação de professores? Será que a Didática está promovendo a prática enquanto componente curricular, valorizando o princípio da indissociabilidade teoria-prática? Que saberes são produzidos pelos licenciandos de Pedagogia como expressão da prática vivenciada na disciplina de Didática?

A cultura ocidental, alicerçada na valorização da teoria em detrimento da prática, imprimiu uma concepção de ensino arraigada no intelecto e na razão, destituída de significados práticos e, portanto, um ensino conservador, encerrado em conteúdos de caráter "enciclopédico", pautado na transmissão-assimilação de conhecimentos. Nesse contexto, ergue-se o Ensino Superior e nesse modelo identificamos certa resistência para a inserção do componente prático e sua integração à teoria. Por outro ângulo, a sobreposição da prática à teoria também pode imprimir um caráter meramente técnico e instrumental à formação de professores. Para Diniz-Pereira (2011, p. 213):

Vários grupos progressistas e comprometidos com a questão da formação de professores nas universidades temem que a ênfase na dimensão prática possa reforçar as ideias conservadoras e retrógradas que limitam a formação docente ao mero treinamento de habilidades necessárias ao ensino, ou seja, concepções meramente técnicas e instrumentais sobre a formação de educadores.

Ao adentrarmos nas discussões sobre a relação que deve ser fortalecida entre teoria e prática, identificamos, com apoio nos estudos de Martins (2009, p.42-43) duas vertentes que se contrapõem na análise do papel de cada um dos elementos: teoria e prática. A primeira vertente enfatiza a teoria como eixo central e da qual surge a prática, ou seja, "[...] a aprendizagem se realiza fundamentalmente a partir do domínio da teoria. A prática decorre da teoria. Daí a importância do racional, do cognitivo, do pensamento. Nessa concepção a ação prática não é determinante, mas determinada." A segunda vertente, por outro lado, identifica a prática como eixo central, sob a qual se dá a expressão da teoria, nas palavras da autora: "As propostas de pedagogia crítica desse grupo deixam de cingir-se à transmissão-assimilação de conteúdos, ainda que críticos, e caminham na direção da sistematização coletiva de conhecimentos, na qual o próprio processo de fazer passa a ser fundamental como elemento educativo". 
A indissociabilidade entre teoria e prática implica em uma postura em que se concebe a prática não como um fazer guiado e determinado pela teoria, mas a teoria passa a expressar a ação prática, superando a perspectiva reducionista em que se hierarquiza esses elementos em processos de sobreposição. Entendemos que uma influencia a outra, dada sua natureza indissociável e pela relação dialética, material e contraditória, de construção dos processos sociais em que são promovidas.

Nessa prespectiva Martins (2009, p. 18) afirma:

\begin{abstract}
A prática tem me mostrado que esse processo apresenta uma forma para desenvolver um ensino de didática mais articulado com a realidade das escolas onde os futuros professores vão atuar. E mais: a prática tem me possibilitado preparar o futuro professor teórica e praticamente para explicar, compreender e intervir na prática pedagógica numa ação comprometida com as classes trabalhadoras.
\end{abstract}

Para explicar melhor essa relação, entendemos que a Didática não se constitui como manual para ensinar, enquanto receituário, ou como o fazer a prática do professor na perspectiva da racionalidade técnica. $\mathrm{O}$ fazer/saber do professor se constrói na própria prática, mediatizados pela capacidade reflexiva e a Didática, expressão dessa prática, tem papel de "explicação e justificativa das práticas que ocorrem no interior da escola” (MARTINS; ROMANOWSKI, 2015, p. 142).

Considerar a prática como elemento fundante do pensar pedagógico é, sem dúvida uma postura política de valorização dos saberes da experiência, da ação do professor sobre sua realidade material, e surge pelo entendimento que a concretude do real é que impulsiona a consciência do sujeito sobre a realidade, portanto a teoria surge nessa relação e por ela se justifica como impulsionadora da práxis transformadora (MARX; ENGELS, 1986).

Nessa perspectiva, realizamos a pesquisa na disciplina de Didática na Ação Docente, enquanto prática voltada para a formação do pedagogo, promovendo a sistematização do conhecimento por meio da ação coletiva, das interações e da reflexão advinda das vivências a partir do eixo epistemológico em que a teoria pedagógica é expressão da prática (MARTINS, 2009).

\title{
A didática na formação do pedagogo a partir das reflexões dos estudantes
}

Este estudo, como já dito, tem como objeto de análise a Didática na formação inicial do professor a partir das reflexões dos estudantes acerca das suas aprendizagens na disciplina de Didática na Ação Docente. Essa disciplina tem como finalidade ampliar a compreensão dos estudantes acerca dos processos didáticos e sua organização pedagógica por meio da Sistematização Coletiva do Conhecimento.

A Sistematização Coletiva do Conhecimento trata-se de uma proposta de aula e de fazer pedagógico ancorado em um eixo epistemológico que entende o discente como aquele que também sabe, e não somente o professor, alterando as relações na sala de aula e a postura didática - ou seja, valoriza a capacidade crítica e reflexiva 
dos sujeitos, bem como sua capacidade de produção de conhecimentos. Para concretizar essa abordagem, a docente propôs como passos didático-pedagógicos: "(1) Caracterização e problematização da prática pedagógica dos participantes; (2) Explicação da prática mediatizada por um referencial teórico; (3) Compreensão da prática no nível da totalidade, explicitando seus fundamentos; (4) Elaboração de propostas para uma ação prática"(ROMANOWSKI, 2016, p. 7).

Na compreensão de Martins (2006, p. 104) essa proposta metodológica permite que os sujeitos...

[...] passem da condição de receptores passivos de informações sistematizadas, absolutizadas e transmitidas numa relação vertical (de cima para baixo), para a condição de sujeitos que vivenciam, num trabalho coletivo, um processo para obter a sistematização. Assim, eles passam a dominar o processo e o resultado.

$\mathrm{Na}$ busca de analisar as reflexões dos estudantes de Pedagogia acerca da prática vivenciada na disciplina de Didática na Ação Docente, destacando sua contribuição na formação do licenciando, os aprendizados adquiridos e a importância atribuída a esses aprendizados, foi feita uma auto avaliação com uma turma de 31 discentes do referido curso. $\mathrm{O}$ instrumento é composto por 3 problematizações em que no primeiro tópico solicita-se a produção de uma carta para um amigo ou amiga como convite para participar da disciplina. Em sequência, é pedido que proponham um plano de melhoria de seus conhecimentos e prática docente em relação ao campo da Didática. $\mathrm{Na}$ problematização 3, os estudantes enumeram 15 tópicos de aprendizagens estimulados por uma lista a ser classificada de 1 a 10 , em que 10 refere-se ao item mais importante e que mais aprenderam, conforme os objetivos propostos na disciplina. Nesse item segue uma questão aberta em que se solicita ao estudante a descrição de outras aprendizagens relacionadas à disciplina de Didática na Ação Docente.

Após a leitura minuciosa das respostas às questões de auto avaliação, passamos a identificar as categorias centrais que fundamentam os discursos dos estudantes, procurando organizar de modo mais sistemático os dados e proceder com a análise. As categorias identificadas inicialmente foram: Importância da didática; Compreensão da didática e de seus elementos; Relação teoria e prática; Relação docente/discente; Abordagens de ensino e a prática docente; Papel do professor e da educação na sociedade. Após essa primeira organização realizamos nova leitura e passamos a identificar os cruzamentos entre essas categorias, unificando-as e/ou inserindo-as em subcategorias. Assim, decidimos por duas grandes categorias, a saber: Compreensão e importância da Didática e seus elementos (concepção de Didática e sua importância na formação do professor, bem como a percepção do processo de ensino e aprendizagem com destaque para seus elementos); $O$ papel do professor e sua prática docente (destaque para a relação teoria e prática, relação discente/docente, as abordagens de ensino e o papel do professor para a transformação social).

Essas categorias foram importantes para descortinar a compreensão que os discentes conseguiram construir sobre o campo teórico e prático da Didática, levando-nos a identificar os fundamentos teóricos necessários à análise e reflexão que propomos desencadear nessa escrita. 
As categorias, ora apresentadas, compreendem os níveis de aprendizagens obtidos pelos discentes na disciplina Didática na Ação Docente, e correspondem aos objetivos propostos na referida disciplina. Dessa forma, entendemos que as categorias agregam conhecimentos e ações didático-pedagógicas interdependentes, ou seja, ao tempo em que cada uma tem suas peculiaridades, se entrelaçam imbricadas no contexto teórico e prático da disciplina.

Para auxiliar-nos no processo de análise, contamos com o software Iramuteq (Interface de R pour les Analyses Multidimensionnelles de Textes et de Questionnaires) ${ }^{2}$ para o tratamento dos dados. Na organização de nossa escrita optamos por apresentar a sistematização dos dados a partir das ilustrações com a nuvem de palavras obtidas através do Iramuteq. Ao inserir os textos no programa Iramuteq obtivemos a nuvem de palavras que segue:

Figura 1 - Nuvem de palavras da análise textual Corpus Carta

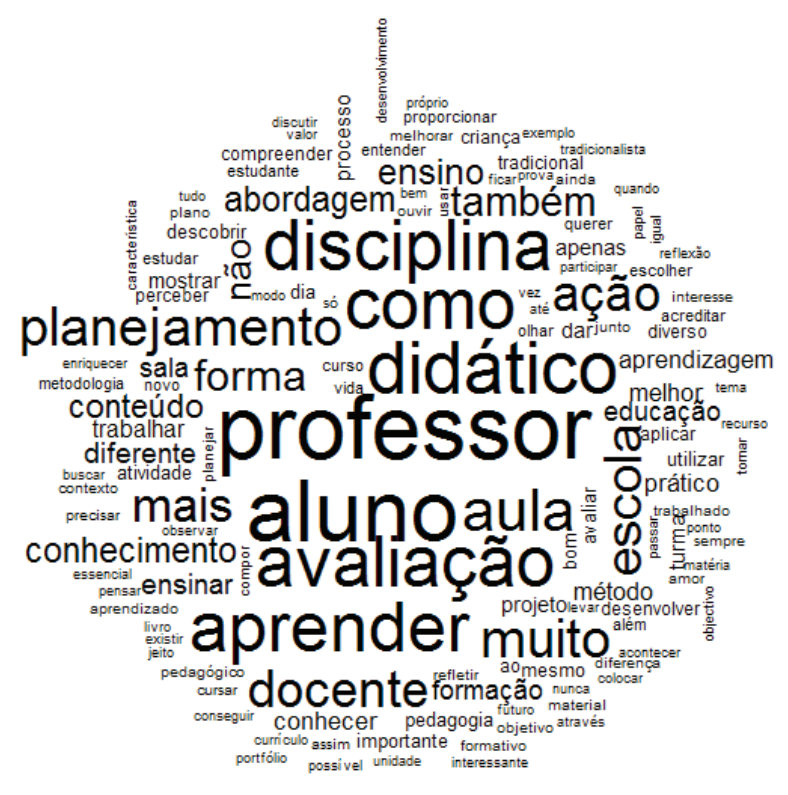

Verificamos que a palavra Professor é a que mais se destaca, isso porque relacionam o foco da disciplina Didática à formação de professores, ressaltando as contribuições dessa disciplina nas práticas pedagógicas e no perfil didático-pedagógico do docente. Muitos registros destacam a Avaliação e o Planejamento como elementos essenciais ao "bom professor", evidenciando que é preciso avaliar bem o aluno e, para tanto, o planejamento é essencial para uma prática assertiva, como descreve o registro dessa estudante: "quem faz planejamento de aula tem propriedade daquilo que transmite, e não apenas reproduz uma lógica de ensino que não ensina; quem planeja a aula alcança o aluno assertivamente" (ESTUDANTE C16) ${ }^{3}$. 
A palavra Aprender vem também com ênfase nos registros, haja vista que os discentes percebem-se como sujeitos em processo de aprendizagem e que estão aprendendo na disciplina de Didática a tornarem-se "bons professores".

\section{Compreensão e importância da didática e seus elementos}

Essa categoria expressa a aprendizagem que os estudantes tiveram quanto a compreensão e importância dos elementos da Didática para o desempenho da prática docente. Entendemos que a aprendizagem atinge esse nível de compreensão do conhecimento por meio da participação do estudante nesse processo de aprendizagem, proporcionando, assim, a construção de novos saberes. Para que isso ocorra, "não poderemos nos contentar em apenas descrever ou explicar [...]" (SANTOS, 2005, p.1). A superação desses dois níveis de conhecimento é a busca do porquê, ou seja, da "compreensão", considerado, por este autor, o nível de maior aprofundamento do conhecimento.

Nessa perspectiva, identificamos que a maioria dos estudantes passou a compreender os objetivos, conteúdos, metodologias, avaliação, planejamento, as abordagens de ensino, dentre outros conteúdos fundamentais para o desempenho da prática pedagógica docente atribuindo um novo significado para o conhecimento da Didática na formação de professores, conforme ilustra a nuvem de palavras. Vejamos alguns registros apresentados pelos estudantes da disciplina Didática na Ação Docente:

[...] A Didática na Ação Docente, lhe ensina, mostra como é a prática em sala de aula, quais são as diferentes abordagens de ensino, diferentes metodologias, tipos de planejamento, como o módulo, a unidade, o projeto político pedagógico, que foi o que eu mais gostei (ESTUDANTE C2).

Percebi que o planejamento dá a forma pela qual o conteúdo será ministrado, permitindo a nós professoras, as escolhas sobre os métodos, sobre quais atividades serão propostas, quantidade de tempo aplicada em cada atividade, compondo assim a programação para uma aula que enseje um aprendizado qualitativo e significativo, para alcançar o objetivo que é a aprendizagem do aluno (ESTUDANTE C17).

Esses registros expressam a compreensão que os estudantes tiveram quanto aos componentes que envolvem o processo de ensino e aprendizagem na prática pedagógica do professor. Apontam a importância que eles têm nesse processo e dão ênfase ao planejamento visto como o instrumento de organização do trabalho pedagógico.

Com relação à importância atribuída à Didática, identificamos que boa parte dos discentes, ao tempo em que compreenderam o campo da Didática, passaram a valorizá-la descobrindo sua importância para a formação do professor. A disciplina caracterizou a docência no imaginário dos discentes, assim como promoveu um novo olhar sobre o fazer pedagógico. As respostas dadas pelos discentes às questões caracterizam a Didática como uma disciplina essencial na formação inicial do professor e a percebem como capaz de contribuir para a melhoria da prática docente, na medida em que proporciona análises e reflexões relacionadas com as abordagens de ensino que 
trazem os elementos necessários ao processo pedagógico, tais como: objetivos, conteúdos, metodologias e avaliações, além dos princípios e fundamentos da ação docente.

Com base na análise dos dados, identificamos que os conhecimentos trabalhados na disciplina foram fundamentais para transformar a concepção dos estudantes acerca da prática docente e da condução de um processo pedagógico, explícito em seus depoimentos. Para ilustrar selecionamos alguns trechos dessa escrita:

Durante o meu curso de Pedagogia, tive a oportunidade de cursar a disciplina de Didática na Ação Docente. Confesso que no início da disciplina fiquei um pouco confusa e não conseguia fazer relação com muitas coisas, porém com o passar dos semestres as coisas começaram a fazer sentido e eu passei a perceber como todo o trabalho docente se dá através da Didática. Hoje as abordagens de ensino, todas as metodologias, os planejamentos, as avaliações, enfim, a forma como as instituições e os professores promovem a formação e a aprendizagem passaram a fazer sentido para mim. (ESTUDANTE C8).

Com essa disciplina pude entender melhor sobre como é a prática docente nas escolas, que vai muito além dos muros das escolas. Compreendi como os conteúdos, objetivos, métodos de avaliação e recursos didáticos são escolhidos e trabalhados pelas professoras. Aprendi que cada escola utiliza uma abordagem de ensino, que antes acreditava serem as mesmas coisas (ESTUDANTE C10).

Nos depoimentos dos estudantes podemos perceber que além dos conteúdos aprendidos e apreendidos por eles, a disciplina possibilitou-lhes a tomada de consciência da importância da Didática na formação do professor e na sua trajetória profissional, a partir de análises e reflexões sobre a prática docente no contexto escolar. O despertar dessa consciência, construída ao longo da disciplina Didática na Ação Docente, se deu pela participação dos discentes no processo de ensino e aprendizagem por meio de atividades didático-pedagógicas realizadas de forma interativa e em coletividade, surgindo, assim, um novo perfil de estudante, mais crítico, dinâmico, reflexivo, dentre outras características, que contraria a visão cartesiana em que o estudante é percebido como uma tábula rasa nesse processo. De acordo com o pensamento de Marx e Engels, a consciência do homem sobre uma dada realidade ocorre na interação dele com essa realidade. É na relação mediada pela reflexão crítica que o homem transforma a realidade ao mesmo tempo que é transformado por ela, ou seja, é na práxis, atividade humana prático-crítica, que ocorre a consciência humana (MARX; ENGELS, 1986).

Encontramos nos textos dos estudantes, ao apresentar a importância da Didática, referência a capacidade da disciplina em solucionar as dúvidas e questionamentos apresentados por alguns discentes quanto ao conhecimento didático e sua aplicabilidade no contexto escolar. Esses discursos expressam uma inquietação comum aos estudantes das licenciaturas, que é a necessidade de materializar produzindo saberes advindos do campo prático no contexto da sala de aula com os conhecimentos trazidos do campo teórico. Nesse sentido, os cursos de formação de professores ao enveredarem por uma matriz curricular fundamentada na indissociabilidade entre prática, teoria e prática, passam a compreender a prática percebendo-a como nos alerta Martins (2009, 
p. 47): “[...] a prática não é dirigida pela teoria, mas a teoria vai expressar a ação prática dos sujeitos. São as formas de agir que vão determinar as formas de pensar dos homens." Portanto, entendemos que é papel da Didática estimular a reflexão sobre o campo profissional e prático do professor valorizando as dúvidas, as inquietações e os relatos trazidos pelos estudantes enquanto potência que problematiza o fazer docente. Os relatos a seguir ilustram bem nossa análise:

\begin{abstract}
Essa disciplina nos proporciona a adentrar em um universo de questionamentos e reflexões. As dúvidas de como aplicar tais ideias dentro do ambiente escolar, nos faz refletir em quais caminhos queremos delinear nossa trajetória (ESTUDANTE C22).
\end{abstract}

Dentre as disciplinas voltadas para a prática docente nos cursos de formação de professores, a Didática se configura como fundamental por compreender conhecimentos que tratam da docência, um dos eixos dos princípios básicos da formação inicial e continuada do professor. Nesse sentido, as Diretrizes Curriculares Nacionais, para a formação inicial e continuada em nível superior de professores, identifica as características e dimensões da iniciação à docência que devem estar expressos nos Projetos Pedagógicos e Curriculares dos Cursos de Licenciatura e em cursos de formação pedagógicas para graduados, seja primeira ou segunda licenciatura. $\mathrm{O}$ enfoque dessas dimensões está em sua maioria voltado para o campo de ensino da Didática ao propor saberes pedagógicos e estudos de contextos educacionais, habilidades relativas às técnicas de ensino e reflexões críticas sobre processos pedagógicos e de aprendizagens.

$\mathrm{O}$ Art. $7^{\circ}$ dessas Diretrizes reporta-se às dimensões da iniciação à docência, tais como compreender o contexto escolar, planejamento da ação docente, avaliação do processo educativo, compreensão dos fundamentos didáticos, compreensão do currículo escolar, são identificadas na maioria dos relatos dos estudantes da disciplina em análise, quando trazem, claramente, a importância da Didática na formação inicial docente. Isso significa que a prática pedagógica foi vivenciada de forma participativa e dialógica, na interação entre a professora e estudantes, buscando a compreensão da relação entre os conhecimentos da Didática na formação inicial de professores e seu campo de atuação. "Nesta disciplina é possível um aprofundamento da prática docente que é indispensável para o professor" (ESTUDANTE C9). O pensamento dessa estudante caracteriza a dimensão que o conhecimento da disciplina de Didática na Ação Docente teve para sua formação inicial.

\title{
Papel do professor e a sua prática docente
}

Nesta categoria percebemos que os estudantes desenvolvem um olhar crítico sobre a prática docente ao tempo em que percebem o professor enquanto agente social que contribui para transformar a realidade. Nessa perspectiva, ao analisar a prática pedagógica dos professores nas escolas que visitaram, como proposta da disciplina Didática na Ação Docente, apontam uma ação didática contextualizada em que se supere uma prática tradicional, ou seja, expressam preocupação com uma formação que lhes possibilite desenvolver um perfil docente diferente daquele modelo tão criticado ao longo da história da educação. 
Na nuvem de palavras identificamos a palavra Conteúdo, embora em menor destaque, cercada pelas palavras trabalhar, diferente, buscar contexto, enriquecer metodologias. Nesse sentido, destacamos dois registros: "Muitas vezes ouvimos a respeito da educação deficitária, [...] mas o mais surpreendente é você descobrir [...] que por mais dificuldades ou faltas ou 'exigências' que o currículo nos impõe, afirmo que é possível a educação harmoniosa com transformação do ser humano" (ESTUDANTE C14). Essas palavras foram também enfatizadas em alguns textos e expressam a preocupação descrita acima, ou seja, estão em busca da consolidação de um perfil profissional mais progressista, que valoriza o diálogo, a participação e o pensar crítico, como afirmam: "esses assuntos fazem-nos pensar sobre a educação de uma forma diferente, nela nós conhecemos o tradicionalismo, que nos mostra como os professores antigamente eram disciplinadores, autoritários e o centro do processo de ensino e aprendizagem" (ESTUDANTE C5); ou ainda, "o que eu mais gostei de estudar foi o planejamento por projeto, pois ele é desenvolvido ao redor de um tema e procura reunir com uma inter-relação, todas as disciplinas e o interesse parte do aluno, das experiências dos alunos e de seu contexto" (ESTUDANTE C31). Nesse sentido, concordamos com Romanowski (2010, p. 142-143):

\begin{abstract}
Essa relação conteúdo-forma implica valorizar os conhecimentos que os alunos já possuem e o contexto social em que eles estão inseridos, o que permite avançar no processo de ensino e aprendizagem e na possibilidade de transformação da realidade social. Nesse sentido, o professor, ao conhecer seus alunos, sua realidade, seus problemas sociais, como assevera Martins (1998), estabelece uma relação com a realidade, circunstancia o conhecimento, propicia sua valoração sócio-histórica. A relação decorrente recompõe esse conhecimento em uma nova relação com esses sujeitos e seu grupo social, para transpor-se nas relações sociais. O movimento toma o local para transversalizar com o universal, e isso é constituir práxis social.
\end{abstract}

Então, no entendimento dos estudantes, a proposta metodológica do professor tem relação direta com o conteúdo que estes elegem para trabalhar e seu significado para o grupo, ou seja, conteúdo e forma se alteram mutuamente, pois o conteúdo dá sentido à forma e esta também traz significado ao conteúdo. $O$ professor ao desenvolver um trabalho numa perspectiva tradicional ou progressista passa a significar o conteúdo pelo método, entretanto, se tiver viés crítico, suscita novo significado à forma como este professor conduz a aula.

A partir dessa categoria, ora analisada, identificamos algumas subcategorias que estão relacionadas a postura didática do professor. Dentre elas, os depoimentos trazem a indissociabilidade entre teoria e prática como condição sine qua nom à formação do professor. A nuvem de palavras (figura 1) apresenta com certo destaque a palavra Ação, cercada pelas palavras reflexão, participação, aprendizagem e interesse. Ao nos reportarmos a leitura das cartas, entendemos que a indissociabilidade entre teoria e prática promovida no âmbito da disciplina de Didática foi percebida pelos estudantes e, para eles, a palavra Ação refere-se a valorização da prática como fio condutor do processo de aprendizagem, haja vista que é pela ação prática que é possível desencadear processos reflexivos, estimulando a participação e o interesse dos discentes, facilitando a aprendizagem. Para Martins (2015, p. 87): 
[...] passa a ser fundamental para a Didática a questão da organização dos conteúdos numa perspectiva teórico-prática, na medida em que, nessa perspectiva de sistematização coletiva do conhecimento, a forma define e dá sentido ao conteúdo. Ou seja, a forma de vivenciar, refletir e sistematizar coletivamente o conteúdo em função de um problema prático dá um novo sentido ao conteúdo.

Além da unidade teoria-prática os estudantes também valorizam a interação professor-aluno como elemento importante a ser considerado, por isso o destaque, na nuvem de palavras (figura 1), para duas palavras essenciais ao processo didático-pedagógico - Professor e Aluno, relacionando-os às interações e suas implicações no ensino-aprendizagem. Destacamos os seguintes trechos das cartas: "Durante as aulas a interação com a professora é constante, o que proporciona discussões e conversas sobre todo o processo educacional" (ESTUDANTE C11); e, ainda um trecho que expressa a afetividade nas trocas com a docente: "[...] a maravilhosa e muito competente professora que ministrou essa matéria, com imensurável dedicação e carinho" (ESTUDANTE C30). Segundo Veiga (2012, p. 23) "[...] para o professor desempenhar sua ação de ensinar de forma satisfatória, o vínculo afetivo é imprescindível para tornar a sala de aula um ambiente mais humanizado, mais próximo às características e necessidades dos alunos".

Vale ressaltar que, dos 31 (trinta e um) estudantes que elaboraram a carta destacando os motivos que justificavam cursar a disciplina de Didática na Ação Docente, apenas 9 (nove) não fizeram menção à avaliação. Esse resultado se evidencia na nuvem de palavras, quando "Avaliação" aparece com certo destaque. Observamos que a maioria dos registros apontam a avaliação como definidora dos resultados da aprendizagem do aluno, demonstrando, assim, preocupação com a prática avaliativa, como também descobertas que os ajudaram no repensar dos modelos e pressupostos que subsidiam a avaliação. Vejamos o que esses registros expressam:

E olha, a avaliação é um ponto que você precisa repensar, pois como você me disse: "vou fazer prova tradicional, mesmo", e nas aulas de didática você vai perceber que, por mais que este tipo de avaliação seja muito utilizado ainda, não é o mais correto, que tal você tentar fazer uma avaliação formativa? (ESTUDANTE C24).

Descobri que o medo que tínhamos quando chegava o dia da avaliação, não precisa persistir nos futuros estudantes. Acredite se quiser, a avaliação é muito mais do que aquele dia tenso em que fazíamos a temida prova. A avaliação pode ser completamente diferente e até estimuladora. Ela pode acontecer durante o processo da aprendizagem e aplicada de diversas formas. Eu por exemplo, nunca fiz uma "prova" igual na disciplina de didática, a professora sempre foi muito criativa (ESTUDANTE C1).

Os registros dos estudantes trazem um novo olhar para a avaliação, descontruindo suas concepções quanto a prática avaliativa tradicional, exclusivamente voltada para os resultados da aprendizagem após julgamentos de "bons" ou "maus" alunos, associados aos que "querem alguma coisa" e aos que "não querem nada", prática muitas vezes inculcada pela escola nos alunos e reforçada pela família e pela sociedade, estendendo-se nas práticas avaliativas dos professores ao longo de sua docência. $\mathrm{Ob}$ - 
servamos que os estudantes passaram a ter essa percepção a partir de sua participação no processo de aprendizagem proporcionado pela disciplina já citada anteriormente neste texto, compreendendo que a avaliação é um elemento significativo nesse processo tal como evidencia o seguinte registro: “[...] tampouco eu imaginava que a avaliação fizesse parte do processo ensino e aprendizagem, [...]. É um ato complexo que exige de nós, profissionais da educação, um olhar mais apurado, ultrapassando a simples correção para chegar a um juízo de valor, daí sua importância." (ESTUDANTE C17). Além disso, passaram a identificar também que o conhecimento sobre avaliação não só favorecia a quem ia ser professor, mas também aos que vivenciam esse processo educativo como estudante. Vejamos o que afirma essa estudante: "[...] mesmo que o objetivo não seja ser um docente [...], estudá-la só enriquecerá seus conhecimentos, afinal saber como é avaliado e os procedimentos que os seus professores utilizam com sua turma auxiliará em sua formação acadêmica e pessoal”(ESTUDANTE C4).

\section{Segundo Wachowicz (2012, p.139):}

[...] a avaliação, feita pelo sujeito que aprende, seleciona as aprendizagens significativas, para incorporá-las à consciência pela interiorização. É um processo complexo, porém fascinante, porque transforma conhecimentos em pensamentos, e estes em atitudes.

Dentre a diversidade de concepções sobre avaliação existentes, chamou-nos atenção a compreensão dos estudantes, indicando-nos que a prática de avaliação vivenciada na disciplina Didática na Ação Docente, a partir da inserção deles no processo de aprendizagem, proporcionou a construção de novos significados para a avaliação, expressos de forma consciente. "A tomada de consciência do processo é o que há de mais importante na aprendizagem, porque pode tornar-se uma atitude, quando trabalhada durante um tempo sistemático e com a intencionalidade da formação humana" (WACHOWICZ 2012, p.143).

Nesse sentido, podemos dizer que proporcionar situações de ensino e aprendizagem nesse processo de construção do conhecimento, em que professor e estudantes interagem de forma compartilhada e dialogada, é compreender esse processo em sua totalidade. "Talvez mesmo pudéssemos progressivamente abandonar a palavra ensino e permanecer com a palavra e o conceito de aprendizagem, pois na concepção dialética todos os protagonistas da ação educativa aprendem enquanto trabalham" (Ibid., p.153). Por meio dessa interação entre os sujeitos do processo educativo vão surgindo diversos saberes, elaborados de forma individual e coletiva, que despertam formas de ensinar e de aprender diferenciadas, mediadas por um enfoque que valoriza a participação, o diálogo, a criatividade, a reflexão, dentre outros contributos que dão vitalidade ao processo educativo.

\section{Segundo Romanowski (2007, p. 56):}

Os sujeitos em interação com o conhecimento, com a cultura, por meio da linguagem, da ação, da experiência, dos processos internos de elaboração do pensamento e do enfrentamento das contradições produzem outras respostas, em última instância, conquistam, produzem conhecimentos. 
Dando continuidade à análise dos dados coletados na pesquisa, apresentamos o gráfico a seguir, que traz o mapeamento dos objetivos da disciplina Didática na Ação Docente, demonstrando os resultados da aprendizagem e o grau de importância da referida disciplina expressa pelos estudantes. Essa questão está contemplada na autoavalição, citada e explicada anteriormente, da seguinte forma: "Das aprendizagens no campo da Didática numere de 1 a 10 por ordem crescente de importância (a mais importante é 10) e que você considera que mais sabe". Vejamos, na íntegra, o que aborda cada tópico de aprendizagem no campo da Didática e a pontuação atribuída pelos estudantes: (1) As abordagens de ensino conseguindo distingui-las - 105 pontos; (2) O conceito de didática - 103 pontos; (3) Os elementos didáticos: definição de objetivos, seleção de conteúdos, proposição de procedimentos didáticos e avaliação - 113 pontos; (4) Como analisar a prática pedagógica das escolas - 128 pontos; (5) Como elaborar um planejamento de ensino - 88 pontos; (6) Distinguir os diferentes modelos (tipos) de planejamento de ensino - 140 pontos; (7) Como elaborar uma proposta de avaliação - 121 pontos; (8) Como analisar criticamente uma proposta de avaliação - 105 pontos; (9) Descrever os conceitos de avaliação - 128 pontos; (10) Comparar técnicas de ensino - 110 pontos; (11) Utilizar adequadamente recursos de ensino 148 pontos; (12) Trabalhar em grupo colaborativamente - 112 pontos; (13) Ler e sintetizar textos em didática - 89 pontos; (14) Como analisar e entender um texto de didática - 77 pontos; (15) Apresentar sugestões didáticas para a prática docente - 124 pontos. O gráfico 1 traz o resultado da somatória, atribuída pelos estudantes, para cada item apresentado.

Gráfico 1 - Aprendizagem no campo da didática

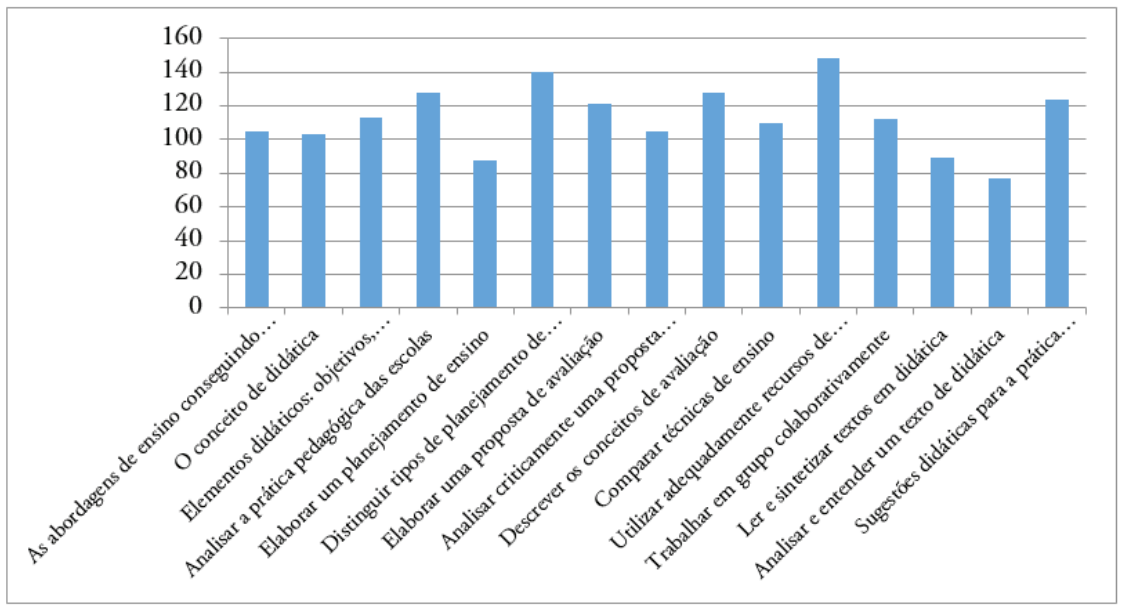

Fonte: Autoavaliação dos estudantes realizada na disciplina Didática na Ação Docente no Curso de Pedagogia 
De acordo com o enunciado da questão, os estudantes assinalaram, em ordem crescente, o item que eles consideraram mais importante e que tinham aprendido mais. Isso significa dizer que eles se sentem mais seguros em determinados conteúdos do que em outros, expressando sua aprendizagem no campo da Didática. Os resultados apontam que o conteúdo mais aprendido refere-se a "utilizar adequadamente recursos de ensino", ou seja, este item corresponde a um dos objetivos da disciplina e implica também em sua proposta metodológica que, ao trabalhar com recursos de ensino, procura valorizar a unidade teoria e prática por meio de um processo que se dá de forma individual e coletiva, possibilitando, assim, a construção de novas aprendizagens a partir da interação entre os sujeitos desse processo, professor e estudante, vivenciadas na instituição formadora e no campo de atuação, a escola.

Dessa forma, o estudante compreende que os conhecimentos construídos e vivenciados no contexto de sua formação inicial, além de lhe proporcionar uma aprendizagem significativa, traz novas produções para a prática docente:

Dificilmente a professora nos dá aulas expositivas, em que ficamos somente ouvindo suas explicações, na maioria das vezes montamos grupos nos quais estudamos os textos juntos e discutimos sobre eles e com o restante da turma. Também são utilizadas muitas outras formas para que consigamos construir nosso conhecimento sobre o conteúdo (ESTUDANTE C13).

Os conteúdos trabalhados nessa disciplina em sala, estão sempre acompanhados de livros ou recortes de textos, filmes, vídeos, debates em sala, atividades em grupo, e até mesmo um tipo de júri que aconteceu em sala, que foi uma das atividades de interação que mais me chamou a atenção. Essas atividades [...] nos encantam e me fazem pensar em como quero ser com meus futuros alunos (ESTUDANTE C5).

As estudantes demonstraram que o significado da aprendizagem está relacionado com a realidade em que se situa uma determinada prática, pois é na prática que surgem novas formas de pensar e agir. Portanto, é no processo de ensinar, nas relações entre professor e estudantes, que se configura uma prática pedagógica dialógica, voltada à construção de uma formação emancipatória. "[...] a ênfase do processo desloca-se para a práxis social e a questão central está na relação dialética da compreensão-transformação (MARTINS, 2012, p. 93, grifos da autora).

Já o item que recebeu menor pontuação foi "como analisar e entender um texto de Didática”. Os resultados expressos no gráfico referentes a este tópico demonstram que a aprendizagem é um processo que está relacionado com a maneira como cada estudante se apropria do conhecimento e constrói novos conhecimentos. Os textos estudados no decorrer da disciplina foram trabalhados de formas diferenciadas e na interação entre os discentes e destes com a docente, na busca por materializar novos conhecimentos a partir de atividades estimuladoras e das práticas vivenciadas, pelos estudantes, nas escolas da educação básica. Isto se comprova quando a estudante afirma que: "para estudar os textos dados pela professora aprendemos diferentes modos de estudo, como por exemplo, GVGO (Grupo de Verbalização e Grupo de Observação) (ESTUDANTE C2)". Consideramos, assim, que analisar e entender textos requer um 
nível de conhecimento mais profundo, portanto é um processo que vai sendo elaborado pelo estudante ao longo de sua aprendizagem. Vejamos o que diz essa estudante: "Confesso que no início da disciplina fiquei um pouco confusa e não conseguia fazer relação com muitas coisas, porém com o passar do semestre as coisas começaram a fazer sentido e eu passei a perceber como todo o trabalho docente se dá através da Didática (ESTUDANTE C2)".

De modo geral, os objetivos que desencadearam o processo pedagógico na disciplina de Didática na Ação Docente provocaram mais aprendizagem embora em graus diferenciados entre os estudantes, portanto nos levam a indicar que a construção de determinado conhecimento é um processo tanto individual quanto coletivo, haja vista que a trajetória de cada sujeito é também uma construção única e interna, intransferível e singular. A esse respeito, concordamos com Romanowski (2012, p. 105):

O ambiente da aula é um espaço de vida coletiva, um espaço de relações únicas e originais, semelhantes a um ecossistema para a intensificação da aprendizagem, em que os vínculos dos alunos e dos professores com o conhecimento são acentuados. Professor e aluno transformam-se e transformam o conhecimento em aprendizagem.

Concluímos, que nesse processo dialógico de formação humana, as trocas, a capacidade de reflexão e a criticidade que nos levam a problematizar a realidade são condições imprescindíveis para ampliar essas trajetórias e possibilitar uma formação intensa, cabendo ao professor mediar, estimular e criar novas vivências e novas oportunidades que serão significativas, tanto para o grupo quanto para ele que também aprende enquanto ensina e vice-versa.

\section{Considerações finais}

A partir das análises dos dados coletados na pesquisa e das reflexões suscitadas por meio da construção desse artigo, ampliamos nossa compreensão quanto a disciplina de Didática, como um dos componentes curriculares voltado para a formação da prática docente. Sua contribuição na formação do pedagogo é um dos eixos constitutivos para a docência, como um dos princípios básicos da formação inicial do professor. A Didática envolve aspectos políticos, econômicos, históricos e sociais, evidenciando sua não-neutralidade e as escolhas político-ideológicas que se manifestam no papel do professor, agente político desse processo. Ou seja, as escolhas que esse profissional irá tomar, seja para ministrar uma disciplina meramente técnica ou uma Didática crítica, supõe uma determinada compreensão do papel do professor e sua atuação profissional, situado em um contexto cultural, político e social.

Na perspectiva de propor uma Didática crítica, a disciplina Didática na Ação Docente foi organizada a partir da Sistematização Coletiva do Conhecimento, metodologia que valoriza a construção do conhecimento a partir de uma dada realidade e que entende o professor como sujeito capaz de pensar criticamente seu campo profissional, levando-o, na interação com os outros e com o meio social, à problematização e compreensão de determinada realidade a partir de suas descobertas. A isso se associa também na formação do docente a elaboração de propostas que assegurem mudanças na própria prática. 
Os estudantes ao participarem ativamente do processo didático-pedagógico da disciplina, ampliaram sua autonomia na condução de sua aprendizagem; identificaram e caracterizaram os problemas da realidade escolar, buscando explicações para esses problemas a partir do referencial teórico que fundamenta o seu entendimento; ampliaram a compreensão de situações da docência em sua totalidade; a partir dessa compreensão puderam elaborar propostas de intervenção nesse contexto.

Ao analisar os registros da autoavaliação dos estudantes, podemos dizer que a disciplina Didática na Ação Docente favoreceu uma abordagem metodológica que proporciona aos estudantes uma compreensão do contexto escolar em suas contradições. Essa postura construída pelo próprio sujeito, no caso, os estudantes do curso de Pedagogia, contribuiu para o despertar de suas consciências por meio de reflexões feitas na prática e a partir dela.

Diante dos resultados expressos ao longo do texto, podemos afirmar que a disciplina Didática na Ação Docente contribuiu de forma significativa para a formação dos estudantes do curso de Pedagogia, suscitando reflexões que os ajudam na construção de uma concepção de educação que tem como ponto de partida a prática social problematizada a partir das vivências e experiências dos sujeitos da escola, professores e alunos. A participação dos estudantes nessa disciplina expressa o compromisso e a ousadia que os grupos podem assumir mostrando que na interação entre professora e estudantes, é possível o diálogo, o compartilhamento, a afetividade, a criatividade, dentre outros contributos que permeiam o processo ensino-aprendizagem, mediado por uma prática voltada para a compreensão de que os conflitos gestados nas contradições sociais podem ser objeto de análise crítica para um repensar realidade na perspectiva emancipatória. Portanto, o modus operandi que caracteriza a prática de qualquer professor tem impacto direto na formação que este promove, ou seja, não aprendemos somente conteúdos curriculares explícitos nas matrizes, ementários e planos de trabalho, mas há conteúdos e aprendizados implícitos, inclusive nas formas do respeito à diferença, na perspectiva da potencialização de cada um e de todos dentro do processo.

\section{Referências}

BRASIL, Ministério da Educação. Conselho Nacional de Educação. Resolução No 02 de $1^{\circ}$ de julho de 2015. Define as Diretrizes Curriculares Nacionais para a formação inicial em nível superior (cursos de licenciatura, cursos de formação pedagógica para graduados e cursos de segunda licenciatura) e para a formação continuada. Diário Oficial da União no 124, 2 de julho de 2015, Seção 1, p. 8-12.

DINIZ-PEREIRA, Júlio Emílio. A prática como componente curricular na formação de professores. Educação, Santa Maria, v. 36, n. 2, maio/ago. 2011. p. 203-218.

GATTI, B. A.; BARRETTO, E. S. S.; ANDRÉ, M. E. D. A. Políticas docentes no Brasil: um estado da arte. Brasília, DF: UNESCO, 2011.300p.

IMBERNÓM, F. Formação docente e profissional: formar-se para a mudança e a incerteza. 8 . ed. São Paulo: Cortez, 2010.

MARCELO, Carlos. Formação de professores para uma mudança educativa. Porto: Porto Editora, 1999.

MARTINS, Pura Lúcia Oliver. Didática teórica e Didática prática: para além do confronto. 8. ed. São Paulo, SP: Loyola, 2006. 
Formação inicial de professores no embalo das ações didáticas: possiblidades para a autonomia docente

MARTINS, Pura Lúcia Oliver. A Didática e as contradições da prática. 3. ed. Campinas, SP: Papirus, 2009.

MARTINS, Pura Lúcia Oliver. As formas e práticas de interação entre professores e alunos. In: VEIGA, Ilma Passos Alencastro (Org.). Lições de Didática. 5. ed. Campinas, SP: Papirus, 2012.

MARTINS, Pura Lúcia Oliver; ROMANOWSKI, Joana Paulin. Didática, práticas de ensino e educação básica na formação inicial de professores: uma relação necessária. In.: MARIN, Alda Junqueira; PIMENTA, Selma Garrido. Didática: teoria e pesquisa. Araraquara, SP: Junqueira e Marin Editores, 2015.

MARTINS, Pura Lúcia Oliver. Conteúdos escolares: a quem competem a seleção e a organização? In: VEIGA, Ilma Passos Alencastro (Org.). Repensando a Didática. 29. ed. Campinas, SP: Papirus, 2015.

MARX; ENGELS. A ideologia alemã. São Paulo: Hucitec, 1986.

NÓVOA, A. Para uma formacion de profesores construída dentro de la profession. Revista de Educación. Madrid, n. 350, p. 203-218, set./dez. 2009.

ROLDÃO, Maria do Céu. A formação de professores como objeto de pesquisa: contributos para a construção do campo de estudo a partir de pesquisas portuguesas. UFSCar, Revista Eletrônica de Educação, Vol. 1, No 1, Set. 2007. p. 50-118.

TUTORIAL, Iramuteq. Tutorial para uso de software de análise textual Iramuteq. Disponível em: <www.python.org>. Acesso em 06 de janeiro de 2017.

ROMANOWSKI, Joana Paulin. Formação e profissionalização docente. 3. ed. Curitiba: Ibpex, 2007.

ROMANOWSKI, Joana Paulin. Curso de Pedagogia: formação do professor da educação infantil e dos anos séries iniciais do ensino fundamental. Revista Brasileira de Pesquisa sobre Formação Docente. Autêntica, Belo Horizonte, v. 02, n. 03, p.136-151, ago./dez. 2010.

ROMANOWSKI, Joana Paulin. Aprender: uma ação interativa. In: VEIGA, Ilma Passos Alencastro (Org.). Lições de Didática. 5. ed. Campinas, SP: Papirus, 2012.

ROMANOWSKI, Joana Paulin. Conhecimentos pedagógicos nos cursos de licenciatura e a base comum de formação de professores. In: Joana Paulin Romanowski; Pura Lucia Oliver Martins; Simone Manosso Cartaxo. (Org.). Práticas de formação de professores da educação básica à educação superior. 1ed.Curitiba: PucPress - Editora Champagnat, 2016, v. unico, p. 47-69.

ROMANOWSKI, Joana Paulin. Plano de Ensino da Disciplina Didática na ação Docente. Curitiba, PR: PUCPR, 2016-1.

SANTOS, Oder José dos. Fundamentos sociológicos da educação. Belo Horizonte:

FUMEC, 2005.

SHULMAN, L. S. Those who understand: Knowledge growth in teaching. Educational Researcher, v. 15 n. 2, 4- 31, 1986.

VEIGA, Ilma Passos Alencastro. Ensinar: uma atividade complexa e laboriosa. In: VEIGA, Ilma Passos Alencastro (Org.). Lições de Didática. 5. ed. Campinas, SP: Papirus, 2012.

WACHOWICZ, Lílian Anna. Avaliação e aprendizagem. In: VEIGA, Ilma Passos Alencastro (Org.). Lições de Didática. 5. ed. Campinas, SP: Papirus, 2012. 
Marly Macêdo - Joana Paulin Romanowski - Pura Lúcia Oliver Martins

\section{Notas}

${ }^{1}$ Roldão entende compósito como a totalidade do conhecimento em que as relações são estabelecidas sem que se anule as fronteiras entre os campos, mas que mantém a unidade na diversidade.

${ }^{2}$ Segundo seu tutorial o IRAMUTEQé um software gratuito e com fonte aberta, desenvolvido por Pierre Ratinaud (Lahlou, 2012; Ratinaud \& Marchand, 2012) e licenciado por GNU GPL (v2), que permite fazer análises estatísticas sobre corpus textuais e sobre tabelas indivíduos/palavras. Ele se ancora no software R (www.r-project.org) e na linguagem Python (TUTORIAL, 2016, p.1).

${ }^{3}$ Identificação dos registros das cartas produzidas pelos(as) estudantes, uma das questões contidas na autoavaliação.

* Doutoranda em Educação pela Pontifícia Universidade Católica do Paraná, Curitiba, Paraná, Brasil.

** Professora doutora da Pontifícia Universidade Católica do Paraná, Curitiba, Paraná, Brasil.

*** Professora doutora da Pontifícia Universidade Católica do Paraná, Curitiba, Paraná, Brasil.

\section{Correspondência}

Joana Paulin Romanowski - Pontifícia Universidade Católica do Paraná, Centro de Teologia e Ciências Humanas, Área de Educação. Rua Imacula Conceição, 1155, Prado Velho. CEP: 81611970. Curitiba, Paraná, Brasil

E-mail: marly-macedo10@live.com - joana.romanowski@gmail.com - pura.oliver@pucpr.br

Recebido em 04 de junho de 2017

Aprovado em 21 de agosto de 2017 